\title{
Economic Burden in Direct Cost of Chronic Obstructive Pulmonary Disease at a Tertiary Care Teaching Hospital: A Prospective Observational Cohort Study
}

\author{
Kruti D. Patel ${ }^{*}, 1$, Tarachand Lalwani ${ }^{2}$ and Kartik Shah ${ }^{3}$ \\ K.B. Institute of Pharmaceutical Education Research and Education ${ }^{1,2}$, Gandhinagar. Department of Pharmacology, NHL Municipal \\ Medical College Ahmedabad, Gujarat. ${ }^{3}$
}

\begin{abstract}
Background: Chronic Obstructive Pulmonary Disease (COPD) is a disease of significantly increasing in terms of economic burden due to its increasing prevalence and high costs. In India because of growing pressure on the health care budget, appropriate reasoning of current expenditure and future investments in public health care becoming a priority. Objective: To evaluate Burden of cost in patients of Chronic Obstructive Pulmonary disease. Material Method: A prospective, observational, non-interventional, cohort study was carried out over a period of six months for Chronic Obstructive Pulmonary Disease (COPD) inpatients at medical wards of Sheth V. S. hospital, Ahmedabad, Gujarat, India. Burden of cost had been evaluated as a part of Pharmacoeconomic. Direct medical and non-medical cost were included in the burden of cost. From the drug rate manual of hospital, cost for drugs and investigation were calculated. Result: Total numbers of 70 patients in which 53 were male and 17 were female with mean age of $60.21 \pm 10.29$. Minimum total direct medical cost was Rs. 864.00 and maximum was Rs. 5876.00 with a mean \pm SD $2418.12 \pm 839.73$, in which medicine cost was high. Minimum total direct non-medical cost was Rs. 149.00 and maximum was Rs. 1069.00 with a mean \pm SD $528.10 \pm 212.72$, in which additional charges was high. Minimum total direct cost was Rs. 1103.00 and maximum was Rs. 6945.00 with a mean \pm SD 2946.22 \pm 1009.23. Direct medical cost contribute $82 \%$ and direct non-medical costs contribute $18 \%$ of total direct cost. Conclusion: COPD has a substantial impact on health-care costs particularly for hospitalization. Pharmacoeconomic evaluation of COPD is essential to obtain optimal therapy at lowest price and alternative treatment plans to gain appropriate health care services Costs of COPD were exceptionally low in India compared to data obtained from developed countries.
\end{abstract}

Keywords: Chronic Obstructive Pulmonary Disease, direct medical cost, Pharmacoeconomic.

\section{INTRODUCTION}

Pharmacoeconomic research is the process of identifying, measuring, and comparing the costs, risks, and benefits of programs, services, or therapies and determining which alternative produces the best health outcome for the resource invested. ${ }^{1}$ Pharmacoeconomic can be defined as a branch of health economics which deals with the measurement of both the costs and consequences of therapeutic decision making. ${ }^{2}$ Most clinicians have little exposure to health economics, as it is a relatively new discipline in the health sciences. Pharmacoeconomical research is primarily driven by the principle that financial resources are limited and that organizational needs generally exceed available resources. ${ }^{3}$ Assessing the clinical effectiveness of any new health care intervention, including medications, is paramount in determining the role of the new intervention in clinical practice. But the new intervention provide only a modest advantage (or no advantage) over existing treatment, usually at higher cost. In the case pharmaceutical interventions, Pharmacoeconomic attempts to measure if added benefit of one intervention is worth the added cost of that intervention. ${ }^{4}$ Health care costs have been
Submitted Date : 21-06-2014 Accepted Date : 09-09-2014

DOI: 10.5530/ijopp.7.3.11

Address for correspondence:

Dr. Kruti D. Patel

Department of Pharmacology \& Clinical Pharmacy, K.B. institute of Pharmaceutical Education and Research, Gh-6, Sector-23, Gandhinagar, Gujarat. E-mail: krutipatel101090@ gmail.com

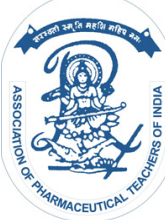

www.ijopp.org 
increasing each year more than the average rate of inflation. This continued increase in costs has resulted in a need to understand how limited resources can be used most efficiently. Clinicians want their patients to receive the best care and outcomes available, and payers want to manage rising costs. ${ }^{4}$ Chronic Obstructive Pulmonary Disease (COPD) is defined by the Global Initiative for Chronic Obstructive Lung Disease (GOLD) as: "A preventable and treatable disease...characterized by airflow limitation that is not fully reversible. The airflow limitation is usually progressive and associated with an abnormal inflammatory response of the lung to noxious particles or gases" ${ }^{5}$ COPD is currently the fourth leading cause of death ${ }^{6}$ in worldwide. ${ }^{7}$ In $2005,>11.6$ million adults $(6.8 \%)$ in the United States were diagnosed with COPD $^{8,9}$ approximately two thirds of whom were aged $\geq 65$ years. ${ }^{10-12}$ the prevalence rates in male subjects of $2.12 \%$ to $9.4 \%$ in studies reported from North are generally higher than $1.4 \%$ to $4.08 \%$ reported from South India. In India it is accounted for $2.8 \%$ of total deaths in 1990 and it is expected to rise to $6.5 \%$ deaths by $2020 .{ }^{13}$ COPD is leading cause of morbidity and mortality worldwide and results in an economic and social burden that is both substantial and increasing. ${ }^{14,15}$ Globally, COPD by 2020 is expected to rise to the third position as a cause of death and at fifth position as the cause of loss of disability adjusted life years (DALYs) according to the baseline projections made in the Global Burden of Disease Study (GBDS). The largest increase in the tobacco related mortality is estimated to occur in India, China and other Asian countries. Cigarette smoking is the major risk factor for COPD. Roughly Rs. 32,000 is the annual cost of treatment for acute cases of COPD hospitalization. ${ }^{2}$ COPD is a disease of increasing significance in terms of economic burden due to increasing prevalence and high cost. Treatment of COPD can be costly and health care providers are interested on improvement of disease burden with respect to cost. ${ }^{16}$ New treatments can be costly, however, and health care providers are increasingly interested not only in whether treatments can offer improvements in disease burden, but also whether they offer value for money. Economic evaluation aims to establish the value of a new treatment by bringing together available evidence on the efficacy, effectiveness and costs of that drug compared to an alternative management strategy, such as an existing treatment. ${ }^{5}$ It is important to consider all aspects of the burden of a disease using a range of outcome measures — not only morbidity and mortality — but also the effect on patient lifestyle and health care resources, and the economic impact on the patient, health care system and society. ${ }^{17}$ COPD exerts a substantial burden on health and health care systems globally and will continue to do so for the foreseeable future. Treatment however can be costly and health care providers are interested in both whether treatments can offer improvements in disease burden and whether they represent value for money. Economic evaluations seek to resolve this issue by producing results that can be used to inform and assist the decision maker in allocating scarce health care resources. ${ }^{13}$ Goals of management in COPD include reduction of airflow, limitation, preventing and treating secondary medical complications, lessening respiratory symptoms and improving health related quality of life. A Fourth reasonable goal in a cost-conscious environment is to use health-care resources efficiently given the enormous economic impact of the condition. ${ }^{15}$ Increase in prevalence of COPD and duration of illness translates into increase the economic burden. ${ }^{18}$ COPD puts economic burden on patients along with affecting quality of life. ${ }^{19}$ In India because of growing pressure on the health care budget, appropriate justification of current expenditures and future investments in public health care are becoming a priority. ${ }^{2}$ Today's pharmacist must not only be able to evaluate safety and efficacy of drug therapy, but also incorporate a Pharmacoeconomic component. ${ }^{20}$ Currently, there are very little applications of Pharmacoeconomic studies in India. As much as $77 \%$ of the health care spending in India is in the private sector, of which about $86 \%$ borne Out-ofpocket/money. The penetration of insurance schemes in India is very low, estimated at about $10 \%$ of the entire population. This signifies the importance of economic considerations in health care. ${ }^{2}$

\section{MATERIAL AND METHOD}

This was prospective, observational, cohort, noninterventional study conducted in inpatients of tertiary care research hospital (Sheth V.S. hospital,Ellisbridge) Ahmedabad, Gujarat, India for a period of six months. The institutional ethics committee permission was obtained for carrying out this study.

\section{Sample selection criteria}

\section{Inclusion criteria}

- Age range: 18-70 years

- Male and female

- Confirmed diagnosis of COPD

- Inpatient

\section{Exclusion criteria}

- Pregnant and lactating women.

- Patient with post tuberculosis lung problem. 
- Patient with Asthma, Allergic Rhinitis.

- Patient with an evidence of pneumonia either at presentation or during follow up.

- Lung cancer.

Patient data relevant to the study was obtained from the sources like Patient data collection form, Patient case note/prescription, Lab reports.

A well designed patient data collection form was developed and used for this study. The data collection form was developed by consulting Physicians and staffs of pharmacology department. The following information like patient demographic details (name, age, reason for hospitalization, duration of illness, smoking history, etc), direct medical costs (drug used, laboratory tests, hospital charges) and direct non-medical costs (diet charges, other expenses) was collected from data collection form.

The total direct cost covers direct medical and direct non-medical cost by using patient case note/ prescription all medicine costs were noted and day to day follow up while attending the ward rounds. The direct medical cost covers the direct medicine cost, laboratory cost and hospital charges, these were obtained from hospital pharmacy slips, lab reports and lab bills, and hospital charges.

Cost had been counted for each patient based on hospitalization (From day of admission to discharge). The cost of discharge medication had not been included in this study. The medicine cost, lab Findings charges,
Diet charges and additional charges were noted down from Drug Rate Manual of Pharmacy Department of Sheth V S General Hospital, Ahmedabad.

All information relevant to the study was collected at the time of admission to till the day of discharge and the collected data of cost-of-illness was subjected for suitable statistical analysis. Analysis was done by using SPSS 22.0 and Microsoft Excel 2008. Result of Descriptive statistics had been represented in mean with Standard deviation, frequency, percentage and range. $\mathrm{P}$ value is $<0.05$ was accepted as statistically significant. Fisher Exact test for determining statistical significance among various groups. Results on continuous measurements are presented on Mean \pm SD (Min-Max) and results on categorical measurements are presented in Number (\%).

\section{RESULTS}

Patient recruitment for the study was carried out from January 2014 to April 2014. During this time period 72 patients with COPD were screened and enrolled into the study based on previously mentioned Inclusion and Exclusion Criteria. Finally, out of 72 patients 70 patients with COPD are enrolled in this study. The COPD patient's age details were shown in (Figure-1)

Out of 70 patients $76 \%$ patients were male $(n=53)$ and $24 \%$ were female $(n=17)$ with a mean \pm SD of age $60.21 \pm 10.29$. (Figure-2)The ratio of male: female is 3.11:1. The patients participated in the study were stayed in hospital (mean \pm SD value of $5.57 \pm 1.93$.) (Table-1)

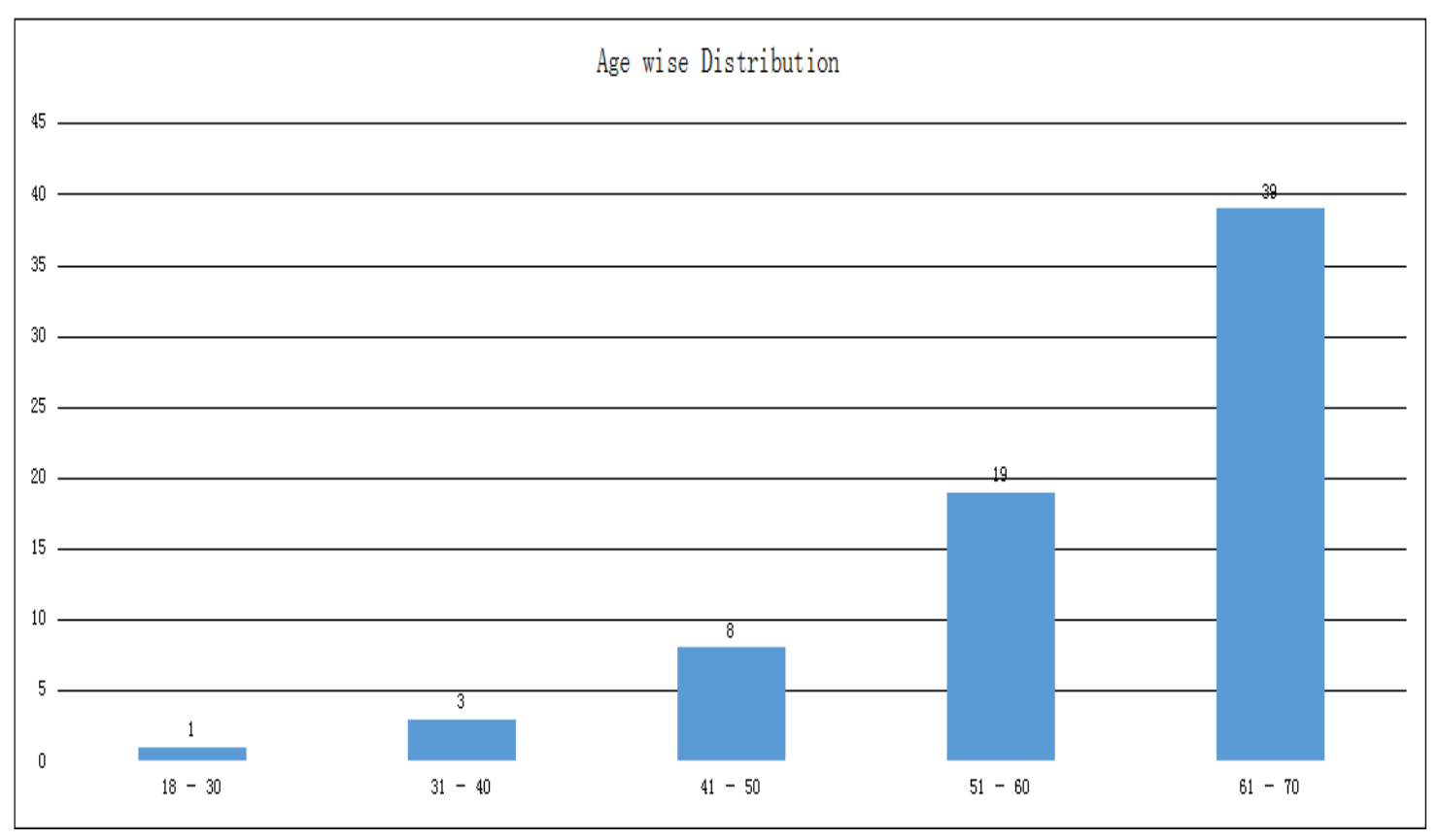

Figure 1: Age wise Distribution 


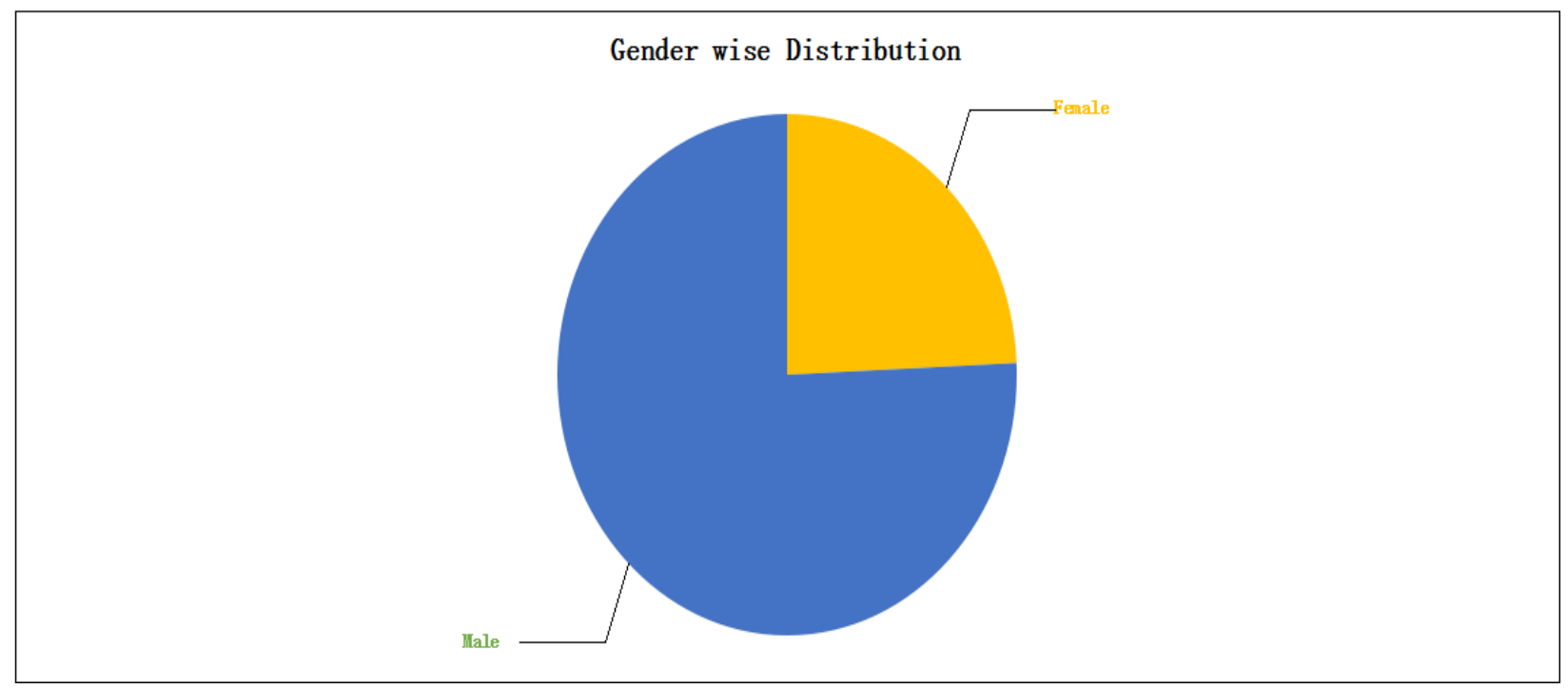

Figure 2: Gender wise distribution

\begin{tabular}{|c|c|c|}
\hline Hospital Stay (In days) & Number of patients & Percentage \\
\hline $1-5$ & 23 & 32.9 \\
\hline $6-10$ & 44 & 62.9 \\
\hline $11-15$ & 03 & 4.3 \\
\hline Total & 70 & 100.0 \\
\hline Duration of illness & Number of patients & Percentage \\
\hline $1-5$ & 30 & 42.9 \\
\hline $6-10$ & 27 & 38.6 \\
\hline $11-15$ & 11 & 15.7 \\
\hline $16-20$ & 02 & 2.9 \\
\hline Total & 70 & 100.0 \\
\hline
\end{tabular}

Out of the 70 Patients $81.43 \%(\mathrm{n}=57)$ patients having complain of breathlessness, $54.29 \%(\mathrm{n}=38)$ patients were having complain of common cold, $48.57 \%(n=34)$ were patients having Dyspnea, followed by $42.86 \%$ $(n=30)$ having Expectoration and 25.71\% ( $\mathrm{n}=18)$ having complain of Cough. (Figure-3)

$54.2 \%(\mathrm{n}=38)$ patients were current smoker, 28.57\% $(\mathrm{n}=20)$ patients had a past history of smoking and 17.1 $\%(n=12)$ patients were non-smoker. (Table: 2 )

The total direct cost is the sum of the direct medical cost and direct non-medical cost. Direct medical cost involves the total medicine cost, lab test charges and hospital charges. Direct non-medical cost involves the diet charges and other expenses directly related to the patient.

Direct medical cost minimum, maximum, mean and SD was Rs. 864.00, 5876.00, 2418.12 and 839.73 respectively in which medicine cost was found to be more. Direct non-medical cost minimum, maximum, mean and SD was Rs. 149.00, 1069.00, 528.01 and 212.72 respectively in which travel expense was found to be more followed by food expense. The mean total direct cost was Rs. 2664.67 with SD of 2030.76 (Table 3). 


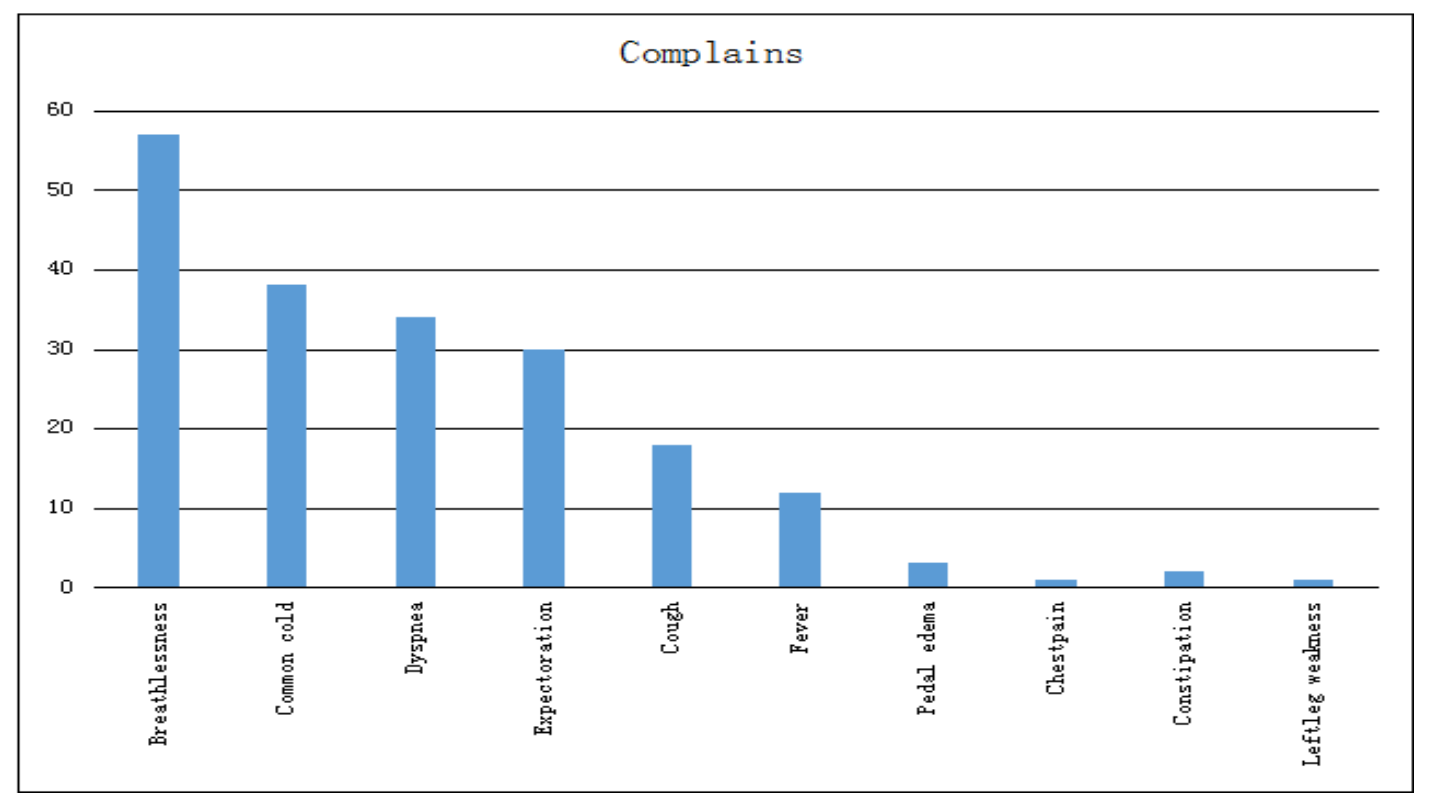

Figure 3: Complains of patients

Table 2: Details on alcohol and smoking status

\begin{tabular}{ccc} 
Smoking Habits & Number of patients & Percentage \\
\hline Non-smoker & 12 & 17.14 \\
Smoker & 38 & 54.29 \\
Past smoker & 20 & 28.57 \\
Alcohol consumption & Number of patients & Percentage \\
Alcoholic & 28 & 40.00 \\
Non-alcoholic & 42 & 60.00 \\
Total & 70 & 100.00 \\
\hline
\end{tabular}

\section{Table 3: Summary on distribution of cost analysis of COPD patients}

\begin{tabular}{lllll}
\hline Cost analysis & Minimum (Rs.) & Maximum(Rs.) & Mean & SD \\
\hline \hline Total Medicine Cost & 204.00 & 2054.00 & 1183.98 & 390.91 \\
Lab Findings charges & 240.00 & 3980.00 & 1017.57 & 578.12 \\
Hospital charges & 80.00 & 440.00 & 216.28 & 74.23 \\
\hline $\begin{array}{l}\text { Total Direct medical Cost(Med cost+ } \\
\text { Hospital cost+ Lab Cost) }\end{array}$ & $\mathbf{8 6 4 . 0 0}$ & $\mathbf{5 8 7 6 . 0 0}$ & $\mathbf{2 4 1 8 . 1 2}$ & $\mathbf{8 3 9 . 7 3}$ \\
\hline $\begin{array}{l}\text { Diet charge } \\
\text { Other expenses }\end{array}$ & 90.00 & 660.00 & 336.42 & 113.11 \\
$\begin{array}{l}\text { Total Direct Non-medical Cost( Diet } \\
\text { charge+ other expenses) }\end{array}$ & 29.00 & 539.00 & 217.01 & 124.05 \\
& 149.00 & 1069.00 & 528.01 & 212.72 \\
Total direct Cost & $\mathbf{1 1 0 3 . 0 0}$ & $\mathbf{6 9 4 5 . 0 0}$ & $\mathbf{2 9 4 6 . 2 2}$ & $\mathbf{1 0 0 9 . 2 3}$ \\
\hline \hline
\end{tabular}


The smoking habit of COPD patients shown total direct medical cost more than 2000 compared to nonsmoker with $P$ value of 0.0034 . The Hospitalization stay of COPD patients shown total direct medical cost more than 3000 compared to less than 6 days of hospitalization with $\mathrm{p}$ value 0.0034 .

\section{DISCUSSION}

The knowledge about the cost of illness of different disease is helpful in planning and achieving relevant health policies intervention. ${ }^{14}$ Most of the studies were estimated based on administrative and population data and use a prevalence based cost-of-illness approach..$^{21-23}$ Other study use data from health-care databases ${ }^{24}$ and one study ${ }^{10}$ identified a group of patients with COPD from medical records quantified retrospectively the use of medical resources in recent years. As per the available literature, this is the first follow-up study of a cohort of patients with COPD aimed at quantifying prospectively the direct costs in Gujarat. This study tried to evaluate the burden of cost in known case of COPD patients at Sheth V S hospital, Ahmedabad which is a part of Gujarat settings. There were very few studies in India which concentrated on cost-of-illness in COPD patients. The present study clearly provided the baseline information for comparing with other similar studies at the level of country and the world.

This study revealed the incidence of inpatients of COPD is $6.48 \%$ which included incidence of hospitalized male COPD patients was $4.91 \%$ and female was $1.57 \%$. The previous study showed incidences of COPD in both gender were $2.12 \%$ to $9.4 \%$ and $1.4 \%$ to $4.08 \%$ in male and female, respectively done by Gindal SK et al. ${ }^{13}$ another study showed higher incidence between $6.5 \%$ to $7.68 \%$ in both gender done by Mckay AJ et a ${ }^{25}$ Among 70 patients of present study population, 53 were male and 17 were female, because of smoking habit was higher in male than female as it is the major risk factor for COPD. The ratio of male to female patients came out as 3.11:1. It was similar as study done by Orneck T et $a .^{16}$ and lower than the study done by Ramnath $\mathrm{KV}$ et al. ${ }^{2}$ in North-Indian tertiary care hospital.

The next component of the study is to find out whether there is any association of different age group of patients and the incidence of hospitalization for COPD. The mean age of study population was 60.21 \pm 10.29 which is similar as per one study. ${ }^{2}$ In present study higher number $(n=26)$ of COPD patients are found in age group of 61-70 years for hospitalization. The similar result were found in a study ${ }^{2}$ showed higher number of hospitalized COPD patients in 61-70 age group. The reason for the higher incidence in this group is due to severe disease condition by increase in age. As the COPD is irreversible, it requires continuing medication and as the increasing age it requires special medical care such as hospitalization. So the higher age is one of the responsible factor for frequent hospitalization. On another hand, past history of smoking habit is directly proportional to the hospitalization of aged patients.

COPD causes an accelerated depreciation of lung function overtime compared with the average of predicted level for healthy person, and is further accentuated by smoking. This study revealed that 54\%, 28\% and $12 \%$ patients were current smoker, ex-smoker and non-smoker, respectively. It is similar as the studies ${ }^{14,26,27}$ and altered in a study ${ }^{16}$ that were $8.4 \%, 54 \%$ and $37.6 \%$ patients were current smoker, ex-smoker and Non-smoker, respectively. In present study the duration of illness of COPD were $42.9 \%, 38.6 \%$ and $18.6 \%$ in group of $1-5,6-10$ and $>10$ years, respectively. In another study ${ }^{2}$ it was higher in both group of 6-10 and $>10$ years of group of duration of illness. However studies have been aimed at quantifying the burden of the disease. Most of these Studies are estimated based on administrative and population data and use a prevalence based cost illness approach. Others studies used

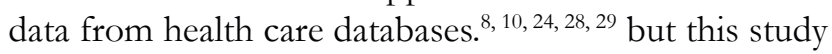
is a follow up study of inpatients admitted with COPD aimed at quantifying prospectively the total costs which include direct medical costs and Direct Non-medical costs.

Direct Medical Cost: Direct medical cost is the sum of medicine cost, lab findings charges and hospital charges. $1 \%$ of the patients had hospital charges Rs $>400$, when compared with the other cost-of-illness study, Ramnath $\mathrm{KV}$ et $\mathrm{al}^{2}$ the hospital charges was less in this study since it was carried out in Semi-government hospital. In some patients the total direct medical cost was high because of co-morbidities. From the total direct medical cost $23-58 \%$ cost is because of the respiratory related drugs, $10-23 \%$ is because of the antimicrobial drugs. In some patients nebulizer prescribed were not available at pharmacy store of the hospital and patients had to purchase from the outside pharmacy store, which having the more cost compare to those nebulizer available at pharmacy store of the hospital. Due to this burden of cost was high in those patients. It is prefer to prescribe the drugs that available at pharmacy store of the hospital. Drugs used for treatment of COPD accounted for $30.2 \%$ of total direct costs. Patterns of treatment recorded in the study did not follow current guidelines, as an example, $70 \%$ of patients were receiving inhaled corticosteroids and combination of bronchodilator and inhaled corticosteroids, while only $16.7 \%$ were receiving the beta- 2 agonist when compared with the study ${ }^{28}$ 
showed drug treatment cost of $40.8 \%$ of total direct cost.

Direct Non-Medical Cost: Total Direct non-medical cost is the sum of Diet charges and additional charges compared with Ramnath KV et al study ${ }^{2}$ in Karnataka which included travel expenses with Diet charges and additional charges in direct non-medical cost. In present study the travel expenses were not included in patient medication file and because of it was only observational study, direct contact with patients was restricted. The mean of total direct non-medical costs was $528.10 \pm$ 212.72 which is higher than the study done in rural, charitable service oriented hospital which incorporated free food services. ${ }^{2}$

Total Direct Cost of the patient: The total direct cost of the patients is the sum of total direct medical cost and total direct non-medical cost. The mean cost of average 6 days for the treatment of COPD was 2946.22 Rs was lower than that reported by Veettil SK et al. ${ }^{14}$ and mark Miravitless et al. ${ }^{8}$ in the treatment cost for COPD in India and Spain, respectively. Reason for the calculated total direct cost was less due to this study being conducted in a Semi-government hospital. There is huge reduction in the cost of drugs and investigations as compared to the private hospitals. A study is having total direct cost 20\% higher than the present study but were probably lower than most countries in Europe or the United States. ${ }^{8}$ This is testimonial that treatment costs in India is much less compared to most other developed countries. The division of the total direct cost in the present study was $82 \%$ medical and nonmedical cost a meagre $18 \%$ which is similar as reported by Ramnath KV et al. ${ }^{2}$ and Veettil SK et al. ${ }^{14}$

In present study the smoking habit of COPD patients shown total direct medical cost more than 2000 compared to non-smoker. The Hospitalization stay of COPD patients shown total direct medical cost more than 3000 compared to less than 6 days of hospitalization. According to the inpatient data available in the present hospital there were an average 25 patients COPD patients per month or about 300 patients per year. The mean total direct medical cost for COPD patients for 6 day stay was found out to be 2946.22 Rs. Extrapolating this to the total 300 patients admitted with COPD in this institution alone comes to around 8,88,866 Rs per year. The findings in this study were not representative of cost burden suffered by patients undergoing treatment in other private hospitals. A simple example was the costs of drugs and Hospital Charges. This study calculated costs for drugs and hospital Charges for 6 days 1122 Rs. While a similar treatment in a private hospital would be costs Rs. $3442.24 .^{14}$
Because COPD is highly prevalent and can be severely disabling, medical expenditures for treating COPD can represent a substantial economic burden for societies and for public and private health insurers worldwide. Nevertheless, very little economic information concerning COPD is available in the literature today. Studies of the economic burden of illness have been conducted in only a few developed countries. Although studies of direct medical-care costs may be less relevant to the developing world, one might hypothesize that the indirect burden of COPD in developing nations may be substantial and important.

To reduce the frequency of hospitalization due to COPD it was found from this study that prior immunization for COPD should take into consideration for known case of COPD. Influenza vaccine should be administered in the fall of each year (October and November) during regular medical visits or at vaccination clinics.

In summary, Costs of management of COPD are low in semi-government hospitals in India as compared to data obtained from developed countries. By taking into consideration the predicted increase in mortality and morbidity due to COPD, the cost of treatment will pose a major economic burden in a highly populated country like India. The formulation of strategy to tackle these impending crises is of prime importance.

\section{CONCLUSION}

The study concludes that the Pharmacoeconomic evaluation of COPD is essential to obtain optimal therapy at lowest price and alternative treatment plans which helps the poor and middle class patients to gain appropriate health care services. With ever increasing health care costs, value added care provided to the patients by individual health care institution needs to be further researched. The development of Pharmacoeconomic is at an infancy stage in India at the moment, despite the rapid growth of clinical research. Costs of the medicines are growing constantly. In a country with scarce resources and an ever-growing population with diverse health care needs, health economics (Pharmacoeconomic evaluation) plays a pivotal role in determining the delivery of equitable and cost-effective health services

\section{LIMITATION}

This study provides a preliminary estimation of the cost involved in selected population which was not truly representative of the community. This is not exact representative of the cost of burden in COPD patients undergoing for treatment in other hospitals. 
The COPD was not confirmed by any diagnostic test instead of accepted by physician recommendation in present study.

The data related to severity of COPD were not obtained from patient medication file. On the basis of severity, the cost were not classified.

The indirect cost and socio-economic status was not included as patient interaction was restricted.

\section{ACKNOWLEDGEMENT}

Mr. Ganesh Rajput, Head Pharmacist, Sheth V.S. Hospital, Ahmedabad

Dr. Devang Rana, Lecturer, NHL Municipal Medical College, Ahmedabad

\section{CONFLICTS OF INTEREST}

Nil

\section{REFERENCES}

1. Dipiro JP. Pharmacotherapy: A Pathophysiologic Approach. The United states of America Sixth Edition. McGraw-Hill Companies; 2005.

2. Ramanath KV, Sabith JK. Pharmacoeconomic Evaluation of Acute Exacerbations of COPD Treatment in a Rural Tertiary Care Hospital. Int $\mathrm{J}$ of Pharmace sci and res. 2012; 3(4): 1155-60.

3. Ahuja J, Ahuja M. Pharmacoeconomic. Natl Med J India. 2004; 17(2): 80-2.

4. Rascati KL. Essentials of Pharmacoeconomics. The United states of America; Lippincott Williams and Wilkins. 2009; 73(5):

5. Helen J, Andrew H, Mike G. Pharmacoeconomic in COPD: lessons for the future. Int J Chron Obstruct Pulmon Dis. 2008; 3(1): 71-88.

6. Hogan JH, Geddes R, Gonzalez ER. An economic assessment of inhaled formoterol dry Powder Versus Ipratropium Bromide Pressurized Metered Dose Inhaler in the Treatment of chronic Obstructive Pulmonary Disease. Clin Therap. 2003; 25(1): 285-297.

7. Stasrt B, Doshi J, Briesacher B, Wrobel M, Baysac F. Impact of prescription coverage on hospital and physician Costs: A case study of Medicare Beneficiaries with Chronic Obstructive Pulmonary Disease. Clin Therap. 2004; 26(10): 1688-99.

8. Miravitlles M, Murio C, Guerrero T, Gisbert R. Pharmacoeconomic Evaluation of Acute Exacerbations of Chronic Bronchitis and COPD. Chest J. 2002; 121(5): 1449-55.

9. Palen J, Monninkhof E, Valk P, Sullivan SD, Veenstrssa DI. Cost effectiveness of inhaled steroid withdrawal in outpatient with Chronic Obstructive Pulmonary Disease. Thorax. 2006; 61(1): 29-33.

10. Hilleman DE, Dewan N, Malesker M, Friedman M. Pharmacoeconomic Evaluation of COPD. Chest J. 2000; 118(5): 1278-85.
11. Blanchette CM, Gutierrez B, Ory C, Chang E, Akazawa M. Economic Burden in Direct costs of Concomitant Chronic Obstructive Pulmonary Disease and Asthma in a Medicare Advantage Population. J Manag care Pharm. 2008; 14(2): 176-85.

12. Stuart BC, et al. Impact of Maintenance Therapy on Hospitalization and Expenditures for Medicare Beneficiaries with Chronic Obstructive Pulmonary Disease. Am J Geriatr Pharmacother. 2010; 8(5): 441-53.

13. Jindal SK, Gupta D, Aggarwal AN. Guidelines for Management of Chronic Obstructive Pulmonary Disease (COPD) in India: A Guide for Physicians. Int J Chest Dis Allied Sci. 200; 46(2): 137-53.

14. Veettil SK, Salmia M, Rajiah K, Kumar SB. Cost of acute exacerbation of COPD in patients attending government hospital in Kerala, India. Alcoholism. 2012; 30(30): 55-8.

15. Global Initiative for Chronic Obstructive Lung Disease. Pocket Guide to COPD Diagnosis, Management and Prevention: A Guide for Health Care professionals. 2013. Available from http://www.goldcopd.org

16. Orneck $\mathrm{T}$, et al. Clinical factors affecting the direct cost of patients hospitalized with acute exacerbation of chronic pulmonary disease. Int J Med Sci. 2012; 9(4): 285-90.

17. Maureen PM, Molken R, Feenstre TL. The Burden of Asthma and Chronic Obstructive Pulmonary Disease. Pharmacoeco. 2009; 19(2): 1-6.

18. Anna O, Smith J, Miller L, Kavookjian J. An Appraisal of pharmacogenomics evidence of maintenance therapy for COPD. Chest J. 2006; 29(6): 1693708.

19. Wastila LS, et al. Burden of chronic obstructive pulmonary disease in Medicare beneficiaries residing in long term care facilities. Am J Ger Pharmaco. 2009; 7(5): 262-70.

20. Sanchez LA. Expanding the role of Pharmacoeconomic why and how? Pharmacoeco. 1994; 5(5): 367-75.

21. Molken R, Postma MJ, Joore MA. Current and future medical costs of asthma and chronic obstructive pulmonary disease in the Netherlands. Respir Med. 1999; 93(11): 779-87.

22. Jacobson $L$, et al. The economic impact of asthma and chronic obstructive pulmonary disease (COPD) in Sweden in 1980 and 1991. Respir Med. 2000; 94(3): 247-55.

23. Wilson L, Devine EB, So K. Direct medical costs of chronic obstructive pulmonary disease: chronic bronchitis and emphysema. Respir Med. 2000; 94(3): 204-13.

24. Sullivan SD, Ramsey SD, Lee TA. The Economic Burden of COPD. Chest J. 2000; 117(2_Suppl): 5-9.

25. Mckay AJ, Mahesh PA, Fordham JZ, Majeed A. Prevalence of COPD in India: a systematic review. Prim Care Respir J. 2012; 21(3): 313-21.

26. Mittman N, Kuramoto L, Seung SJ, haddon JM, Kennedy CB, Fitzgerald JM. The Cost of moderate to severe Chronic Obstructive Pulmonary disease Exacerbations to the Canadian health care system. Respir Med. 2008; 102(3): 413-21.

27. Jansson SA, Andersson F, Borg S, Ericsson, Jonsson E, Lundback B. Costs of COPD in Sweden according to Disease severity. Respir Med. 2002; 122(6): 1994-2002.

28. Miravitlles M, Murio C, Guerrero T, Gisbert R. Costs of Chronic Bronchitis and COPD: A one year follow up study. Chest J. 2003; 123(3): 784-91.

29. Murthy KJR, Sastry JG. Economic burden of chronic Obstructive pulmonary Disease. National commission on macroeconomics and Health-Burden of disease in India. 2005; 264-71. 